\title{
Decoy bypass for appetite suppression in obese adults: role of synergistic nutrient sensing receptors GPR84 and FFAR4 on colonic endocrine cells
}

\author{
Madusha Peiris (10, ${ }^{1}$ Rubina Aktar, ${ }^{1}$ David Reed, ${ }^{2}$ Vincent Cibert-Goton, ${ }^{1}$ \\ Ausra Zdanaviciene, ${ }^{1}$ Writaja Halder, ${ }^{1}$ Adam Robinow, ${ }^{1}$ Simon Corke, ${ }^{1}$ \\ Harween Dogra, ${ }^{1}$ Charles H Knowles, ${ }^{1}$ Ashley Blackshaw ${ }^{1}$
}

\begin{abstract}
- Additional supplemental material is published online only. To view, please visit the journal online (http://dx.doi.org/ 10.1136/gutjnl-2020-323219).

${ }^{1}$ Centre for Neuroscience, Surgery and Trauma, Blizard Institute, Barts and The London School of Medicine and Dentistry, Queen Mary University of London, London, UK

${ }^{2}$ Gastrointestinal Diseases Research, Queen's University, Kingston, Queensland, Canada

\section{Correspondence to} Dr Madusha Peiris, Neurogastroenterology Group, Queen Mary University of London, London, UK; m.peiris@qmul.ac.uk
\end{abstract}

Received 28 September 2020 Accepted 9 May 2021

Check for updates

(c) Author(s) (or their employer(s)) 2021. Re-use permitted under CC BY. Published by BMJ.

To cite: Peiris $M$, Aktar $R$, Reed D, et al. Gut Epub ahead of print: [please include Day Month Year]. doi:10.1136/

gutjnl-2020-323219

\section{ABSTRACT}

Objective Colonic enteroendocrine cells (EECs) store and release potent anorectic hormones that are key regulators of satiety. EECs express multiple nutrient sensing receptors, particularly for medium-chain fatty acids (MCFAs): GPR84 and FFAR4. Here we show a non-surgical approach with targeted colonic delivery of MCFA, which induces EEC and neuronal activation leading to anorectic effects.

Design A randomised, double-blind, placebo-controlled, cross-over study was performed in obese adults given combined GPR84 and FFAR4 agonists in colonic release capsules before meals. We measured serum hormones, energy intake and appetite perception. Cell type, activation by agonists and hormone/serotonin release were determined in human colonic explants. Mouse colonic afferent nerve responses to nutrients/mediators were recorded electrophysiologically.

Results Subjects receiving GPR84 and FFAR4 agonists had reduced overall calorific intake and increased postprandial levels of PYY versus placebo. Receptors including GPR84 and FFAR4 were coexpressed on human colonic EEC. Activation of GPR84 exclusively induced intracellular pERK, whereas FFAR4 selectively activated pCaMKII. Coactivation of GPR84 and FFAR4 induced both phosphoproteins, and superadditive release of GLP-1 and PYY. Nutrients and hormones convergently activated murine colonic afterent nerves via GLP-1, Y2 and 5 - HT3 receptors.

Conclusions Colonic GPR84 and FFAR4 agonists reduce energy intake and increase postprandial PYY in obese adults. Human colonic EECs coexpress these receptors, which activate cells via parallel intracellular pathways and synergistically evoke hormone release. Further synergism occurs in sensory nerve responses to MCFA and EEC mediators. Thus, synergistic activation of colonic endocrine cells via nutrient receptors is an important target for metabolic regulation.

Trail registration number NCT04292236.

\section{INTRODUCTION}

Gastric bypass surgery, Roux-en-Y gastric bypass (RYGB) in particular, is currently the treatment of choice for obesity and associated type 2 diabetes. ${ }^{1}$ It achieves weight loss and glucose tolerance via several mechanisms including delivery of food to

\section{Significance of this study}

What is already known on this subject?

- The most effective current treatment for obesity and type 2 diabetes is gastric bypass surgery, but it is restricted in availability, irreversible, costly and may cause harm. Shunting of undigested food (including medium chain fatty acid (MCFA)) to the distal gut triggers hormone release by activating enteroendocrine cell (EEC) via specific nutrient sensing receptors.

- Boosting colonic levels of the bacterial product propionate increases hormone release and reduces energy intake in humans, further implicating the colon as a site for metabolic regulation.

What are the new findings?

- Administering a colonic release formulation of MCFA (found normally only in the upper gut) before meals reduced food intake and boosted plasma PYY in obese adults without adverse effects.

- MCFA cooperatively stimulate nutrient receptors, which synergise through different intracellular pathways in EEC to maximise hormone release. This action on colonic EEC leads in turn to synergistic activation of afferent nerves projecting to the central nervous system (CNS).

How might it impact on clinical practice in the foreseeable future?

- The stimuli used in this study were safe and unrestricted for human use; furthermore, side effects were absent.

- Later phase clinical trials in obesity could begin soon after refinement of capsules. We also now understand the biology of an important pathway for regulation of energy intake.

the terminal ileum and colon, where previously naïve nutrient receptors on enteroendocrine cells (EECs) are activated by a wide range of undigested nutrients, ultimately resulting in increased circulating levels of the potent anorectic hormone PYY ${ }^{2}$ and the insulinotropic hormone GLP-1. In addition, 
RYGB alters microbial populations leading to changes in luminal short-chain fatty acid and bile acid concentrations, which also bind to nutrient or bile acid receptors expressed on colonic EECs, collectively contributing to reduced food intake. ${ }^{34}$ Physiologically activated colonic EECs that are capable of responding to a multitude of nutrient stimuli may therefore represent an important target for decreasing food intake via peripherally regulated mechanisms.

Energy intake, appetite and satiety are controlled by several sensory, mechanical and psychological factors with both shortterm and long-term effects. EECs are one important molecular regulator of appetite as they store and release orexigenic (eg, ghrelin) and anorexigenic hormones (eg, GLP-1, PYY and CCK)/transmitters (5-HT) that balance feelings of hunger and satiety. ${ }^{5-10}$ These hormones exert their effects on central pathways such as the appetite centre in the arcuate nucleus that contain AgRP/POMC neurones that respond to neuroendocrine signals leading to reciprocal inhibition of appetite increasing/ decreasing pathways. ${ }^{1112}$ The close apposition of EECs to nerve endings in the gut mucosa also permits local effects of hormones on afferent neurons before these rapidly degrade after release due to effects of enzymes such as dipeptidyl peptidase-IV (DPPIV). ${ }^{13}$

EECs, expressed from stomach to rectum, are traditionally classified according to hormone/peptide content, although emerging evidence suggests hormonal expression shifts during stages of cell maturation. ${ }^{14-16}$ Interestingly, the distal region of the gut has a high density of EECs including GLP-1 and PYY containing L cells and 5-HT containing enterochromaffin (EC) cells. ${ }^{17}$ We have previously shown that nutrient-sensing G-protein coupled receptors (GPCRs) binding to specific amino acids and short/medium/long-chain fatty acids, including GPR84 and FFAR4, are expressed at high levels in the colon. ${ }^{18}$ Due to the variety of nutrient receptors and paucity of EECs relative to colonocytes, it could be reasoned that EECs must respond to multiple stimuli in a concurrent manner to reflect the multinutrient content of human diets. Indeed, costimulation of GPR119, FFAR4 and GPR40 induces synergistic GLP-1 release from mouse colonic crypt cultures ${ }^{19}$ suggesting synergy of nutrient sensing GPCRs may exist in human EECs. We focused on FFAR4 and GPR84 as we and others have shown they: (A) are highly expressed in the colonic region and (B) respond to agonist stimulation by releasing anorectic hormones. ${ }^{18} 20$

The development of new effective medical treatments for obesity will require delineation of molecular mechanisms that underpin the normal physiological processes of nutrientmediated appetite regulation. Sumithran et $a l^{21}$ elegantly demonstrated that even following successful weight loss within an 8 -week timeframe using calorie restriction diets, the anorectic hormone profile of these subjects does not change, even after 52 weeks. This suggests that long-term maintenance of weight loss requires targeting of EEC physiology to boost anorectic hormone release.

The aim of this study was to determine how dual nutrient stimulation may impact EEC activity using in vivo, ex vivo and clinical trial methodologies. The current study, a proof-ofconcept trial in obese volunteers, demonstrates that coadministration of colonic GPR84 and FFAR4 agonists decreases food intake and increases PYY release in active versus placebo. We show that the underlying cellular mechanism is the expression of multiple nutrient sensing receptors on EECs that when stimulated concurrently, synergistically boosts cell activation and anorectic hormone release. Using mouse neuronal recordings, we demonstrate that peripheral afferent neuronal activity is subsequently increased in response to nutrient content and EEC activity.

\section{METHODS}

\section{Ethical approval}

All subjects provided informed, written consent to participate. It was also registered with www.clinicaltrials.org.

\section{Patient and public involvement}

Volunteers for the clinical trial were recruited from the general public after newspaper coverage of the study. Patients undergoing resection were asked to participate in the study on the day of surgery, while biopsies were collected from patients visiting the Endoscopy Unit, both at the Royal London Hosptial, Whitechapel. All patients were told of the types of studies that were being carried out and how their contribution would benefit understanding of essential gut processes. Patients were not involved in the study design but were informed that results would be available by contacting reserachers directly (as per guidance on patient information sheet given to all participants) as well as in open access peer review publications.

\section{Proof of concept obese volunteer study}

We hypothesised that colonic delivery of endogenous GPR184 and GPR124 agonists would reduce food intake and increase circulating levels of PYY and GLP-1. The predefined primary outcome was change in calorific intake, and secondary outcomes included changes in levels of circulating hormones, PYY, GLP-1 and ghrelin. Men and women aged 18-60 years with a body mass index (BMI) of $30-40 \mathrm{~kg} / \mathrm{m}^{2}$ were invited to participate. Potential subjects were excluded if they had previous gastrointestinal surgery, major health problems and/or were taking medication for type 2 diabetes.

\section{Study design}

The study used a double-blind, randomised, placebo-controlled, cross-over design. Twenty subjects were randomised to receive either active treatment or placebo with a 4 -week washout period to account for menstrual fluctuation that can influence appetite with sample size calculated based on previous studies examining similar outcomes to colonic nutrient treatment. ${ }^{22} 23$ Prior to each study visit, subjects were asked to fast overnight from 20:00. At visit 1, weight and height were recorded, and BMI was calculated. At the beginning of each visit, subjects were cannulated via the antecubital fossa to collect blood samples $(3 \mathrm{~mL})$ at baseline $(\mathrm{t}=0)$ and $30 \mathrm{~min}$ intervals until $\mathrm{t}=480 \mathrm{~min}$ ( 8 hours). Prior to each blood sample being taken, subjects were asked to record their levels of hunger, satiety and fullness using $100 \mathrm{~mm}$ visual analogue scales (VAS). ${ }^{24}$

\section{Active and placebo}

Active capsules contained a total of $500 \mathrm{mg} \mathrm{3 \prime 3}$ diindolylmethane (DIM) $(250 \mathrm{mg}$, Olympian Labs), $2100 \mathrm{mg}$ alpha linolenic acid (ALA) contained within perilla oil $(500 \mathrm{mg}, 90 \mathrm{LiCaps}$, Fairvital) and $2400 \mathrm{mg}$ lauric acid (LA) (Sigma Aldrich). Note: DIM $(10 \mathrm{mM})$ and ALA $(100 \mathrm{mM})$ both stimulated human ex vivo colonic tissue in Ussing chambers leading to activation of pERK and pCaMKII pathways, respectively (data not shown). Visually identical placebo capsules were filled with methylcellulose (Sigma). All capsules were coated with Phloral (Intract Pharma Ltd, UK) to ensure capsule delivery and disintegration in the colon. Colonic arrival and release of contents coated with 
Phloral has been demonstrated in volunteers as described by Varum et al. . $^{25}$

The first set of capsules was given 60 min prior to breakfast (time-point 0 hours) and the second 60 min before lunch (timepoint 5 hours). The maximum calorific intake for breakfast was $903 \mathrm{kcal}$ and lunch was $1340 \mathrm{kcal}$, and subjects were asked to eat as much as they desired up to this maximum. Following completion of the meal, the amount of food consumed was quantified and calorific intake calculated. All study visits commenced between 08:00 and 09:00 and were conducted at the Wingate Institute of Neurogastroenterology. Throughout the visit, the nurse/investigator maintained regular communication with the subject to encourage good compliance.

\section{Circulating hormone assay}

Prior to blood collection, EDTA Vacutainer tubes were cooled on ice. Immediately after blood collection, $10 \mu \mathrm{L}$ of DPPIV inhibitor $(50 \mathrm{Nm})$, fluoxetine $(100 \mathrm{Mm})$ and moclobemide $(100 \mathrm{Mm})$ were added to prevent hormone/5-HT degradation. Plasma was collected by centrifugation $(10 \mathrm{~min}$ at $1000 \times \mathrm{g})$, and $1 \mathrm{~mL}$ aliquots were stored at $-20^{\circ} \mathrm{C}$. Total GLP-1, total PYY, active ghrelin and gastric inhibitory polypeptide (GIP) were quantified using a human multiplex kit according to manufacturer's instructions (Milliplex MAP Multiplex assay, Merck Millipore). 5-HT was measured using an ELISA (BA E-5900, Labor Diagnostika Nord) as previously described. ${ }^{18}$

\section{Human colonic tissue collection}

Full thickness samples of human ascending colon were obtained from 4 to 6 patients (five male, median age 53 year, range 31-64 years) undergoing surgery for colon cancer at The Royal London Hospital (Barts Health NHS Trust). All specimens were obtained from patients with non-obstructive tumours that were not occuring in the context of inflammatory bowel disease. Specimens were taken with the permission of the histopathologist following macroscopic examination and were a minimum of $10 \mathrm{~cm}$ away from tumour, resection margins or lymphatic drainage field.

\section{Immunohistochemistry}

Following surgical resection, tissues were fixed in $4 \%$ paraformaldehyde $\left(4^{\circ} \mathrm{C}\right.$ overnight). Tissues were cryoprotected in $30 \%$ sucrose/PBS then mounted in optimum cutting temperature medium. Tissue sections of $10 \mu \mathrm{m}$ were cut on a Cryostat (Leica CM1860), incubated with blocking buffer (Dako, UK) for 1 hour, before primary antibodies were applied overnight $\left(4^{\circ} \mathrm{C}\right)$. Antibody details are provided in online supplemental methods. Tissues were washed (PBS; $3 \times 5 \mathrm{~min}$ ), and species-specific secondary antibodies were conjugated to Alexa Fluor fluorescent dyes (1:400, Thermo Fisher Scientific, UK) applied for 1 hour, before washing (PBS; $3 \times 5 \mathrm{~min}$ ), mounting (Vectashield hard set mounting media, Vector Laboratories, USA) and cover-slipping. Controls with no primary antibody were used in all experiments to check for non-specific secondary antibody binding. Leica DM4000 epi-fluorescence microscope was used to visualise immunoreactivity of sections. To ensure uniformity of acquired images, all sections were orientated and cut in the same manner. Images were captured using MetaMorph software (Molecular Devices, UK) and prepared for figures using Photoshop (Adobe) and PowerPoint (Microsoft).

\section{Ussing chamber experiments}

Human colonic mucosal sheets (from cancer resections) were divided into $1 \times 1 \mathrm{~cm}$ segments, and each segment was mounted in an Ussing flux chamber. We used a method developed by our group for optimised nutrient stimulation of human colonic mucosal sheets. ${ }^{18}$ Briefly, the luminal surface was exposed to $10 \mathrm{~mL}$ nutrient solution, while the basolateral surface was exposed to $10 \mathrm{~mL}$ Krebs solution, for $20 \mathrm{~min}$. All solutions were carbogenated and maintained at $35^{\circ} \mathrm{C}-37^{\circ} \mathrm{C}$. Colonic mucosa was then fixed in $4 \%$ paraformaldehyde overnight.

\section{Ex vivo human tissue hormone release assays}

As previously described, ${ }^{18}$ human colonic mucosa was dissected into small, approximately $0.5 \mathrm{~mm}$ blocks, and each specimen was weighed before incubation with $250 \mu \mathrm{L}$ of carbogenated solutions of buffer (control) or nutrients in a 96-well plate for 15 min (5-HT assay) or $20 \mathrm{~min}$ (hormone assay) at $37^{\circ} \mathrm{C}$. A customised tissue culture medium with $4.4 \mathrm{mM}$ L-glutamine and $6 \mathrm{mM}$ glucose was used in order to ensure cells were healthy but not stimulated with nutrients. Inhibitors were used and hormone/ transmitter levels were evaluated as described above.

\section{Extracellular electrophysiological recordings of mouse proximal colon}

Nerve bundles running alongside mesenteric blood vessels that innervate the proximal region of the mouse colon were identified under a dissecting microscope and drawn into a borosilicate glass suction electrode (Harvard Apparatus, UK) prefilled with Krebs buffer. These comprise both vagal and splanchnic afferent nerves, which were both therefore recorded. However, activation by nutrients and gut hormones is lacking in most studies of spinal afferents, ${ }^{26}{ }^{27}$ suggesting that the afferent fibres we studied are predominantly vagal. Nerve activity was recorded on a Neurolog headstage (Digitimer Ltd, UK), amplified at a gain of $5000 \times$, band pass filtered $(100-2000 \mathrm{~Hz})$ and data acquired $(20 \mathrm{kHz}$ sampling rate; micro1401, Cambridge Electronic Design, UK) to a desktop computer running Spike2 (Cambridge Electronic Design, UK) software. Action potentials were counted using an online spike processor (Digitimer Ltd, UK), and the threshold level for spike processing was set to the smallest identifiable spike (typically $\sim 100 \mu \mathrm{V}$ ).

\section{Data analysis}

For cell counting following immunohistochemistry experiments, five fields of view at $40 \times$ objective, covering the entire section so as to remove image acquisition bias, were analysed from 4 to 6 individual tissue samples. Cells clearly immunoreactive positive, found within colonic crypts and captured completely in field of view, were counted as previously described. ${ }^{18}$ The number of full, unbroken crypts in each field of view was counted to normalise cells/crypt in nutrient stimulation experiments assessing pCaMKII and pERK. Differences between counted cells per sample were assessed for statistical significance using Prism software and $\mathrm{p}<0.05$ was considered significant.

In electrophysiology experiments, analysis was performed offline using the spike sorting function of Spike2 to discriminate afferent nerve activity of individual units. ${ }^{28}$ Units were considered as responders if the increase in action potential discharge during the 5 min luminal nutrient perfusion was greater than $20 \%$ the baseline firing (measured during the 5 min preceding nutrient perfusion). ${ }^{29}$ Data were displayed as mean \pm SEM.

A sample size of 20 subjects was estimated based on calorific intake data from a previous study. ${ }^{23}$ To analyse VAS questionnaires, recorded answers for each time point in active versus placebo was averaged and compared using a two-way analysis of variance and Sidak's multiple comparison test. Changes in total 
A

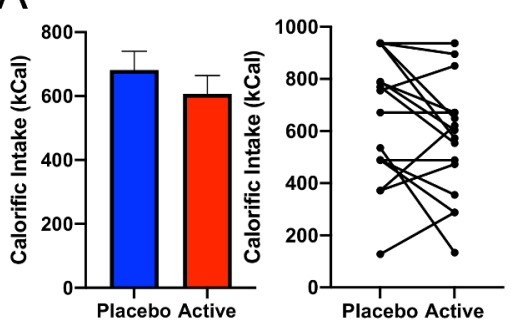

D
B

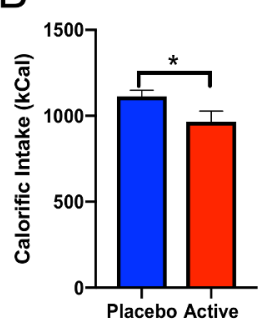

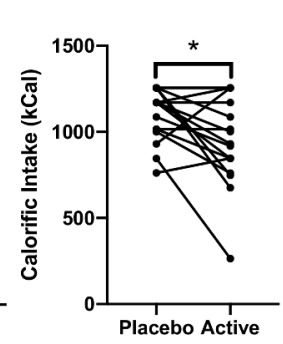
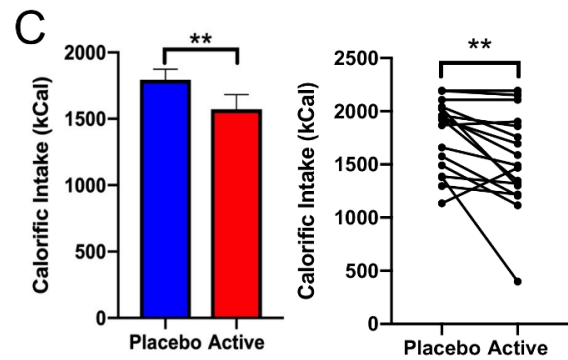

E
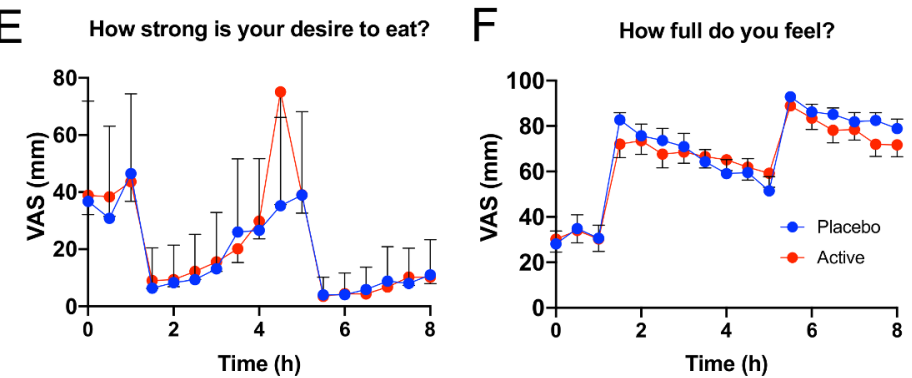

Figure 1 Colonic delivery of nutrient combination to obese subjects significantly reduces calorific intake. (A) Calorific intake at breakfast was unchanged between active versus placebo treatment. (B) Calorific intake at lunch was significantly lower in active versus placebo treatment $(p=0.019)$. (C) Total calorific intake (including calorific intake from breakfast and lunch) was significantly lower in active versus placebo treatment arms ( $p=0.008)$. (D) VAS scores assessing feeling of hunger at each time-point in active versus placebo were unaltered. (E) VAS scores assessing desire to eat was not different between active versus placebo. (F) VAS scores assessing fullness showed no difference between active versus placebo. VAS, visual analogue scale.

calorific intake for active and placebo conditions (relative to time 0 ) were analysed using paired Student's t-test, and a $\mathrm{p}$ value of $<0.05$ was deemed significant. Area under the curve (AUC) for GLP-1, PYY, 5-HT and ghrelin was calculated and compared between active and placebo and analysed using paired Student's t-test. Data were deemed normal following D'Agostino-Pearson omnibus normality test and are presented as mean \pm SEM. A p value of $<0.05$ was considered significant. All data were analysed using GraphPad Prism V.8 software.

\section{RESULTS}

\section{Effect of combined GPR84 and FFAR4 agonist} supplementation in proof-of-concept study

Twenty obese human volunteers who met inclusion criteria (BMI: $30-40$, no major gut surgery, not a type 1 or type 2 diabetic) were recruited to the study (mean BMI: $34.2 \pm 0.46 \mathrm{~cm} / \mathrm{kg}^{2}$ and mean age: $48.9 \pm 2.0$ years). To assess the effect of combined GPR 84 and FFAR4 agonist stimulation, we used 3'3 diindolylmethane and LA as natural GPR84 agonists and perilla oil (containing $60 \%$ alpha-linolenic acid) as a natural FFAR4 agonist. No adverse effects, including nausea or vomiting, were reported by the 20 volunteers when given the active or placebo capsules. Targeted colonic delivery of these compounds significantly reduced calorific intake of the lunch meal (placebo: $1113 \mathrm{kCal}$, active: 965.7 $\mathrm{kCal} ; \mathrm{p}=0.0193$ ) and overall calorific intake (breakfast and lunch meals combined (placebo: $1794.5 \mathrm{kCal}$, active: 1572.7 $\mathrm{kCal}, \mathrm{p}=0.008$ ), a $13.3 \%$ and $12.4 \%$ mean reduction (compared with placebo), respectively (figure $1 \mathrm{~B}, \mathrm{C}$ ). No change in calorific intake was observed of the breakfast meal (figure 1A). Interestingly, there was no difference in subjective ratings of appetite such as feelings of hunger, desire to eat and fullness between the active and placebo treatments (figure 1D-F).

Circulating levels of appetite regulation hormones were assessed as a physiological end-point throughout the study day during both active and placebo stimulations. Coadministration of GPR84 and FFAR4 agonists significantly increased circulating levels of total PYY compared with placebo (active: $\mathrm{AUC}_{\Delta} 474.9 \mathrm{~min} \times \mathrm{pg} / \mathrm{mL}$ vs placebo: $305.7 \mathrm{~min} \times \mathrm{pg} / \mathrm{mL}$, $\mathrm{p}=0.018$; figure $2 \mathrm{~A}$ ). Increased PYY was sustained from 3 hours, when capsules arrive and begin to disintegrate in the colon (figure 2A). ${ }^{25}$ Active GLP-1 levels were not significantly changed following nutrient treatment (active: $\mathrm{AUC}_{\Delta} 190.5 \mathrm{~min} \times \mathrm{pg} / \mathrm{mL}$ vs placebo: $167.9 \mathrm{~min} \times \mathrm{pg} / \mathrm{mL}, \mathrm{p}=0.9661$; figure $2 \mathrm{~B}$ ), nor were circulating levels of 5 -HT (active: AUC $_{\Delta} 635.7 \mathrm{~min} \times \mathrm{ng} / \mathrm{mL}$ vs placebo: $774.4 \mathrm{~min} \times \mathrm{pg} / \mathrm{mL}, \mathrm{p}=0.5830$; figure $2 \mathrm{C}$ ). We also assessed ghrelin levels that did not significantly change in active treatment versus placebo (active: $\mathrm{AUC}_{\Delta} 191.9 \mathrm{~min} \times \mathrm{pg} / \mathrm{mL}$ vs placebo: $508.4 \mathrm{~min} \times \mathrm{pg} / \mathrm{mL}, \mathrm{p}=0.5245$; figure $2 \mathrm{D})$. The basal levels of the hormones PYY (placebo: $89.4 \pm 27.7 \mathrm{pg} / \mathrm{mL}$, active: 94.8 $\pm 36.4 \mathrm{pg} / \mathrm{mL}$ ), GLP-1 (placebo: $12.9 \pm 2.9 \mathrm{pg} / \mathrm{mL}$, active: $14.7 \pm 3.3 \mathrm{pg} / \mathrm{mL}$ ), 5 -HT (placebo: $107.8 \pm 10.2 \mathrm{pg} / \mathrm{mL}$, active $101.3 \pm 26.4$ ) and ghrelin (placebo: $57.1 \pm 21.1 \mathrm{pg} / \mathrm{mL}$, active: $22.9 \pm 5.4 \mathrm{pg} / \mathrm{mL}$ ) were not different between visits.

\section{Expression of nutrient sensing receptors on human EECs}

To investigate nutrient sensing GPCRs on native human EEC, we obtained fresh, macroscopically normal proximal colonic epithelium from surgical resections. Immunohistochemistry revealed that fatty acid receptors GPR84 and FFAR4 were located on EEC; $\mathrm{L}$ cells and EC cells (figure 3A,B), as was the short chain fatty acid (C2-C7) receptor GPR43 and peptone/amino acid receptor GPR92 (online supplemental figure 1A,B), confirming our previous mRNA expression data along the human gut. ${ }^{18}$ The great majority of EEC on which GPCRs were found were EC, since they were 5-HT immunoreactive, whereas the minority were L cells, which coexpressed GLP-1 and PYY (figure 3A,B, online supplemental figure $1 \mathrm{~A}, \mathrm{~B})$. GPCR colocalisation studies showed that the long-chain fatty acid receptor FFAR4 was coexpressed with the medium-chain fatty acid receptor GPR84 on both L cells and EC cells (figure $3 \mathrm{C}$ ). The colonic population of EC cells outnumbered L cells 5 -to- $1 .{ }^{17}$ The degree of GPR120/ GPR84 coexpression observed in EC cells was greater, 33\% vs 


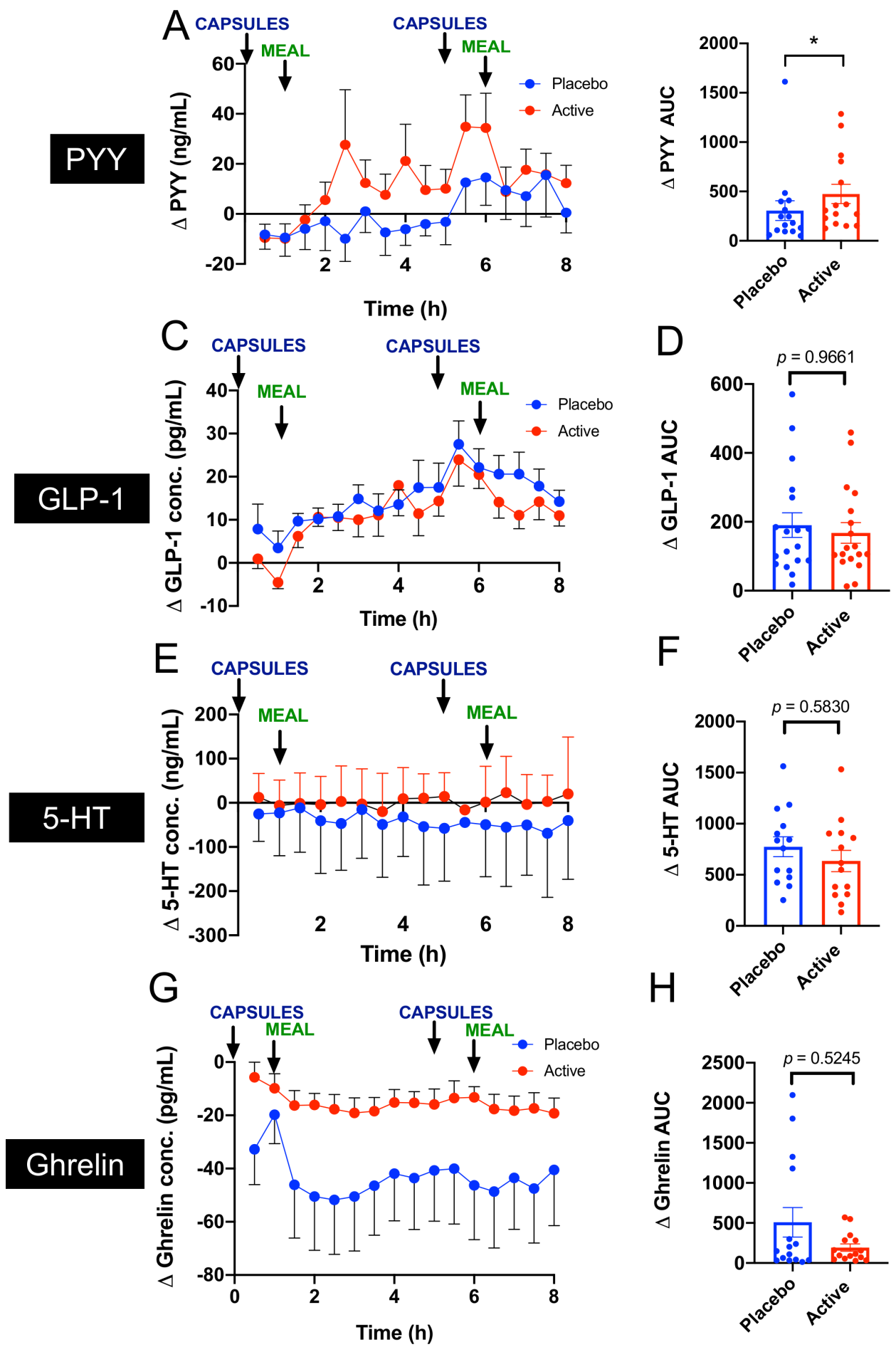

Figure 2 Effect of acute coadministration of 3'3 diindolylmethane (DIM), alpha linolenic acid and lauric acid (LA) on gut hormone levels in obese subjects. (A) Circulating levels of PYY were significantly increased in the active treatment compared with placebo. (B) GLP-1 levels did not significantly differ between active and placebo. (C) 5-HT levels did not significantly differ between active and placebo. (D) Ghrelin levels did not significantly differ between active and placebo. Capsules were given at time 0 and 5 hours, and breakfast was given at 1 hour and lunch given at 6 hours as indicated by arrows.

$6 \%$, respectively (figure $3 \mathrm{C}$ ). FFAR4 also colocalised with the peptone receptor GPR93 on both EEC cell types (online supplemental figure 1D).

\section{Activation of nutrient receptors on human EECs}

We determined if activation of nutrient receptors led to activation of phosphoprotein pathways in human EEC by exposing the luminal surface of colonic mucosal sheets to selected nutrients in an Ussing chamber. This revealed induction of pERK by the selective GPR84 ligand LA $(\mathrm{C} 10,25 \mathrm{mM})$ (figure 4A,B) but not by the potent and selective FFAR4 agonist TUG-891 $(10 \mu \mathrm{M})^{31}$ (figure $\left.4 \mathrm{~F}\right)$. Conversely, pCaMKII was induced by TUG-891 but not by LA, indicating a high degree of selectivity of phosphoprotein pathways for each GPCR (figure 4C,D-F). 

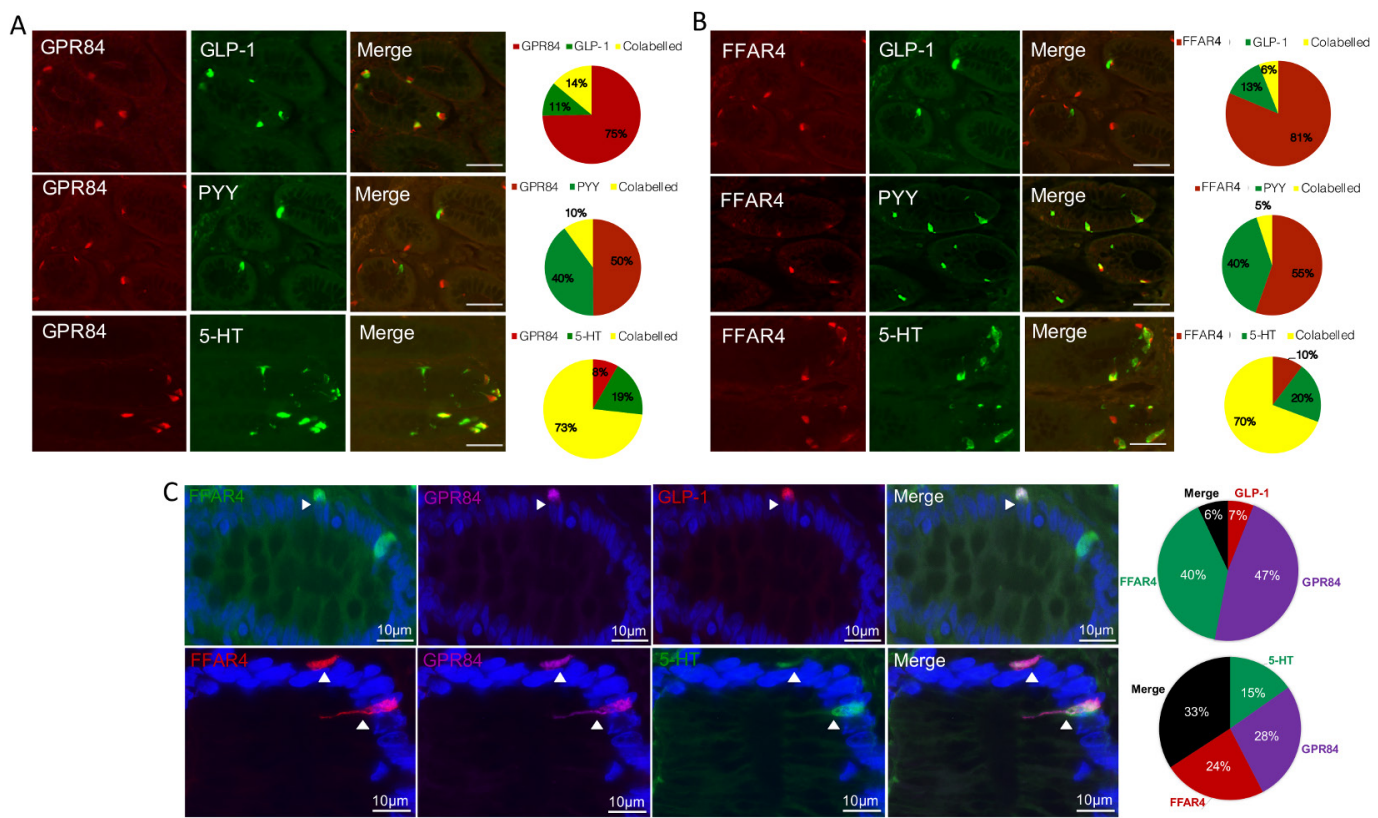

Figure 3 L cells and enterochromaffin (EC) cells coexpress GPR84 and FFAR4 in human proximal colon. (A) GPR84 is expressed on GLP-1/PYY containing $\mathrm{L}$ cells and 5-HT containing EC cells in human proximal colon mucosa. Expression of GPR84 was highest in EC cells, with a smaller population of $L$ cells expressing this GPCR. $n=5$. (B) FFAR4 expression was observed on both GLP-1 and PYY containing $L$ cells, although in a small subpopulation. EC cells, however, expressed FFAR4 in majority of 5-HT containing cells. $n=5$. (C) Top panel: FFAR4 and GPR84 are coexpressed on GLP1 containing $L$ cells, as shown in the merged image. Analysis of coexpression is shown in the graphs where cells were analysed for expressing GLP-1 alone, FFAR4 alone, GPR84 alone and when all three were found expressed on the same cell as shown by 'merge'. $n=5$. Bottom panel: FFAR4 and GPR84 are coexpressed on 5-HT containing EC cells. Analysis of coexpression is shown in the graphs where cells were analysed for expressing 5-HT alone, FFAR4 alone, GPR84 alone and when all three were found expressed on the same cell as shown by 'merge'. $n=5$.

We have previously demonstrated that GPR84 stimulation by LA induces pERK expression in cells including L and EC cells. ${ }^{18}$ Here we show that TUG891 acting on FFAR4 induces pCaMKII expression in $\mathrm{L}$ and EC cells in addition to colonocytes (online supplemental figure $2 \mathrm{~A}, \mathrm{~B}$ ). When colonic mucosal sheets were simultaneously exposed to ligands of both receptors, expression of pERK and pCaMKII was seen in the same specimen (figure $4 \mathrm{E}-\mathrm{G}$ ).

This raised the question of whether different intracellular pathways may contribute synergistically to boost EEC responses to nutrient receptor activation. Incubation with different nutrient stimuli led to different patterns of EE mediator release from colonic biopsies. LA activated release of total PYY, active GLP-1 and 5-HT (figure 4H) but not release of ghrelin and GIP (data not shown). TUG-891 alone released only PYY and GLP-1 (figure $4 \mathrm{H}$ ). Strikingly, in the in vitro study, the combination of TUG891 and LA specifically boosted release PYY and GLP-1 to between two and four times the value for each individual nutrient but did not improve 5-HT release (figure $4 \mathrm{H}$ ).

\section{Downstream effects on mouse colonic afferent nerves}

Mouse afferent recordings were performed to see if stimuli that activate EEC also activate afferent nerves from the same region and if convergence and synergism of signals were continued in this next step of signalling to the CNS. 5-HT 3 , GLP-1 and $\mathrm{Y}_{2}$ receptors are expressed on vagal afferent fibres and mediate nutrient-related signals from the gut to the central nervous system (see also online supplemental figure $3 \mathrm{~B}$ ). ${ }^{32-35}$ Vagal afferents play a key role in initiating satiety. ${ }^{13} 35$ To test the hypothesis that nutrient signals are transduced into afferent signals in the proximal colon by L cell and EC mediators that are located in close proximity to afferent nerves stained with calretinin-a putative vagal afferent marker (online supplemental figure 3 ) $^{36}$ we developed a novel mouse preparation to record afferent activity. Using this model, we studied if convergence and summation occurred with nutrient-evoked afferent responses as we had shown for EEC responses. When LA (25 mM) and TUG-891 $(10 \mu \mathrm{M})$ were coadministered, there was evidence of cooperativity of responses (figure $5 \mathrm{~A}, \mathrm{~B}$ ) but not to the extent seen in EEC responses, suggesting amplification was mainly at the level of the upstream EEC; this is supported by the observation of LA increasing release of GLP-1 and PYY from mouse mucosal tissue (online supplemental figure 4). In another series of experiments, application of exogenous GLP-1 and PYY independently produced convergent effects on $>90 \%$ of fibres (figure $5 \mathrm{C}$ ); 23 single units were tested with GLP-1, 19 of which responded; 34 single units received PYY, 22 of which responded; and 27 single units were tested with 5-HT, 17 of which responded. The $5-\mathrm{HT}_{3}$ receptor antagonist granisetron significantly inhibited the response to 5-HT (online supplemental figure 5). The $\mathrm{Y}_{2}$ receptor agonist CYM 9484 significantly inhibited the response to PYY, and the GLP-1 response was significantly inhibited by the GLP-1 receptor antagonist Exendin 3-39 (online supplemental figure 5). ${ }^{37}$ The responses of afferent units to intraluminal perfusion with LA $(25 \mathrm{mM})$ were reproducible, but absent after preadministration of all three antagonists (online supplemental figure 6), but not after each antagonist was applied individually in separate experiments (not shown).

In a subset of recordings, multiple mediators were applied to the same mouse tissue. In units given both PYY and GLP-1, all $(7 / 7)$ responded to both. The observation that individual single units are able to respond to each of these mediators indicated that receptors for each coexist on the same afferent endings (figure 5C). Furthermore, combination of threshold 

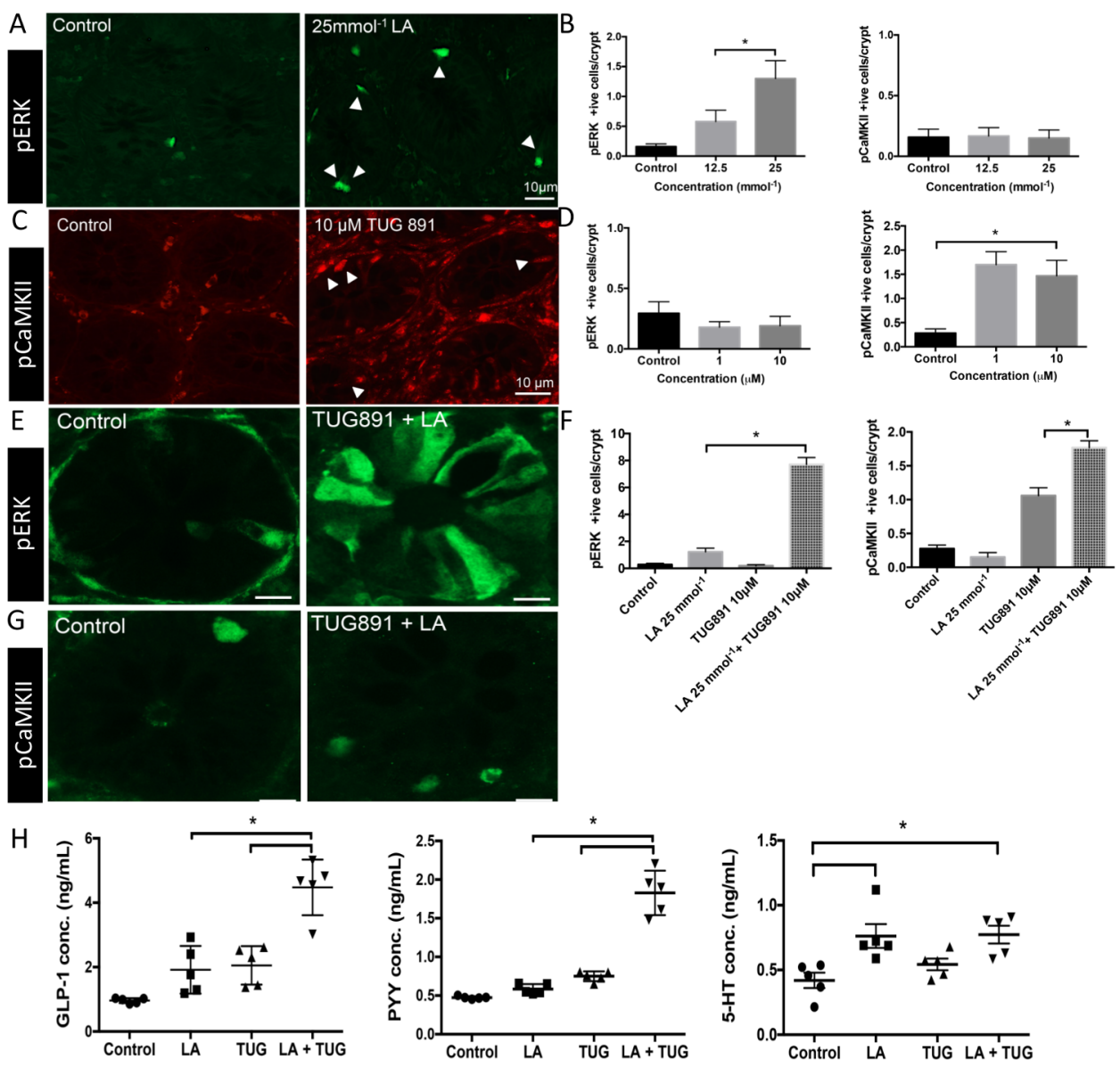

Figure 4 GPR84 and FFAR4 agonists activate separate intracellular pathways that converge to boost release of GLP-1 and PYY. (A) Stimulation of human colonic mucosa with GPR84 agonist, lauric acid $\left(25 \mathrm{mmol}^{-1}\right)$ increases PERK expression in human colonic epithelial cells (green) compared with control buffer. $n=4$. (B) Lauric acid stimulation specifically induces expression of PERK (in a concentration dependent manner) and not pCaMKII, in human colonic mucosa. $n=4$. (C) FFAR4 agonist TUG891 (10 $\mu \mathrm{M})$ increases expression of pCaMKII in human colonic epithelial cells (red) compared with control buffer. $n=4$. (D) TUG891 stimulation specifically induces expression of $p C a M K I I$ (in a concentration dependent manner) and not PERK, in human colonic mucosa. $n=4$. (E) Coapplication of lauric acid $\left(25 \mathrm{mmol}^{-1}\right)$ and TUG891 $(10 \mu \mathrm{M})$ enhances cell activation as measured by PERK immunoreactive cells. $n=5$. (F) quantification of cells positive for PERK showed co-application of Lauric acid $\left(25 \mathrm{mmol}^{-1}\right)$ and TUG891 (10 $\left.\mu \mathrm{M}\right)$ results $^{-1}$ in fourfold increase of positive cells compared with control and single nutrient application. co-stimulation doubled the number of pCaMKII cells compared with single nutrient application. $n=5$. (G) Immunoreactivity for $p C a M K I I$ increased in colonic crypts compared with buffer stimulation in human colonic mucosa. $n=4$. (H) Coapplication of lauric acid $\left(25 \mathrm{mmol}^{-1}\right)$ and TUG891 $(10 \mu \mathrm{M})$ to human mucosal tissue doubles the release of anorectic hormones GLP-1 and PYY compared with stimulation with single nutrient solution. Release of 5-HT is not enhanced by coapplication of GPR84 and FFAR4 agonists. $\mathrm{n}=5$.

concentrations of PYY and GLP-1 evoked powerful responses that were maximal for each fibre (figure 5D), seen also in combination experiments with 5-HT (online supplemental figure 5), indicating that there was convergence and synergism at the level of the EEC and at the level of the afferent ending.

\section{DISCUSSION}

Using a translational approach, we demonstrate that human colonic EECs are a key molecular target for maximising peripherally mediated appetite regulation and offer a novel therapeutic avenue for limiting food intake. We found EECs express multiple nutrient sensing GPCRs and that selective stimulation of GPR84 and FFAR4 in vitro results in activation of separate intracellular pathways leading to synergistic release of anorectic hormones PYY and GLP-1. These hormones may then activate peripheral nerve endings to increase neuronal activity. Importantly, in a proof-of-concept clinical trial in obese volunteers, we demonstrated that co-administration of GPR84 and FFAR4 agonists led to reduced food intake and increased levels of circulating PYY.
The EEC is becoming a key target in metabolic disease because of its role in orchestrating downstream responses in a range of neural, epithelial, endocrine and immune cells. ${ }^{38-40}$ Activation of EECs has long been the focus of several successful clinical strategies to prolong or boost the action or release of GLP-1 and PYY. ${ }^{56}$ We show that colonic EEC are equipped with multiple receptors for nutrients endogenous and exogenous to the colon, which together can trigger a potent endocrine response. Here we have described only two phosphoprotein pathways. These were mainly distinct to the particular cell studied, and there are likely to be several more. ${ }^{41}$ Intracellular pathways linking nutrient and metabolite sensing GPCR with peptide release are poorly understood, especially in EEC. Further research is required to understand allosteric interactions, G-protein coupling and cytoskeletal processes in exocytosis. Additionally, as we have previously reported, ${ }^{18}$ multiple GPCR activation results in entrainment of colonocytes and paracrine effects mediated by $\mathrm{Y}_{1},{ }^{42} \mathrm{GLP}-1^{43}$ and $5-\mathrm{HT}_{3}$ receptors expressed on colonocytes. ${ }^{44}$ The paracrine effects observed may result in changes to absorption, ${ }^{45}$ immune 

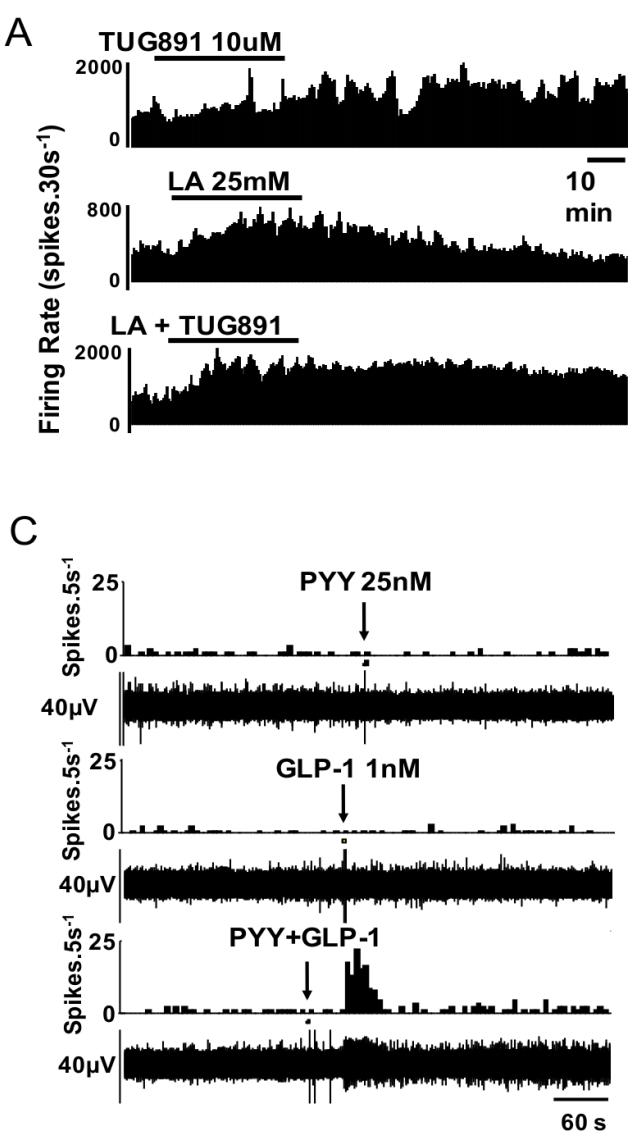

B

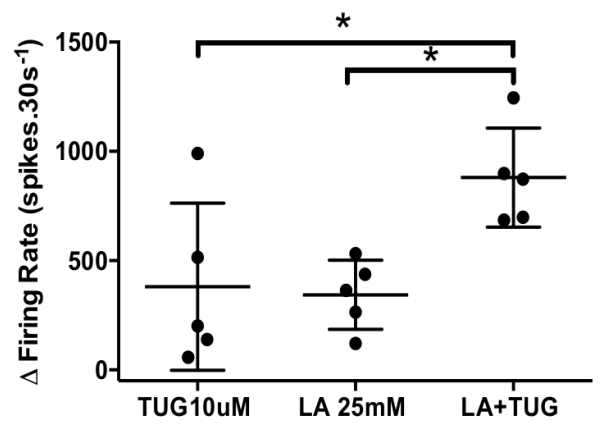

D

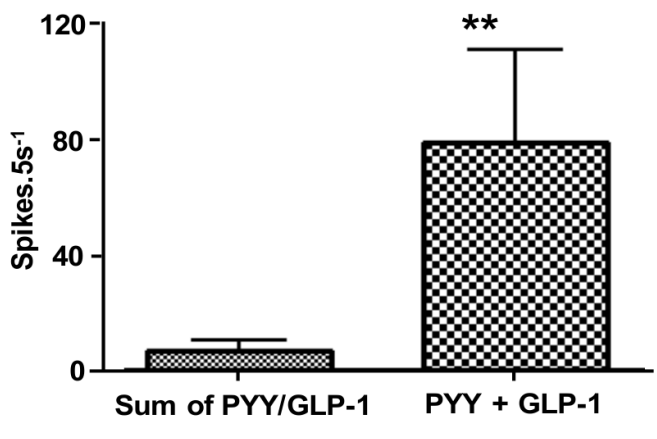

Figure 5 Synergistic effects are exerted on proximal colonic afferents by nutrients and appetite regulating hormones. (A) TUG891 evoked a slowonset response in neuronal firing, whereas lauric acid (LA) had a faster onset effect with greater potency. (B) Combination of TUG891 and LA evoked a synergistic effect on afferent nerve firing rate. $n=5 /$ treatment. (C) Example rate histogram and RAW neurogram records of an afferent unit response to PYY $(1 \mu \mathrm{M})$ and GLP-1 $(1 \mu \mathrm{M})$, administered individually at subthreshold concentration and together. (D) Graph showing group data for responses to PYY and GLP-1 alone and in combination $(n=7)$.

cell/cytokine activity ${ }^{46}$ and crypt proliferation, ${ }^{43}$ some of which may have influenced food intake in this study.

Our data show that nutrient mediated processes continue downstream of the EEC, with afferent nerves from the colon also showing convergent responses to EEC mediators GLP-1 and PYY acting on GLP-1 and Y, receptors, respectively. Several studies show afferent endings innervate the mucosal epithelium and terminate in close apposition to EECs. ${ }^{27-49}$ Small intestinal vagal afferents respond to CCK and 5-HT among others in a convergent way in some species, ${ }^{32}$ but not others. ${ }^{50}$ As PYY is the major EEC mediator in the lower gut, ${ }^{51}$ we sought to demonstrate convergence of PYY signalling relative to other mediators. The degree of convergence between EEC mediator-evoked responses suggested concurrent expression of $5-\mathrm{HT}_{3}, \mathrm{Y}_{2}$ and GLP-1 receptors on afferent endings and is supported by studies that have shown the receptors exist on vagal afferents. ${ }^{334}{ }^{39} \mathrm{We}$ observed that these receptors acted super-additively to activate colonic afferents, which follows since they comprise both ion channel and G-protein coupled receptors with distinct downstream pathways. Therefore, afferent nerves can convey detailed information about the immediate epithelial hormonal environment to the CNS, providing a higher resolution map to the CNS than hormones arriving via the circulation.

We have shown two clear levels of convergence in this system: the first within the EEC itself, and the second in action of EEC mediators on afferent endings that subsequently signal to the central nervous system. Our proof-of-concept trial, mirroring findings from earlier ex vivo tissue experiments, demonstrated both reduced food intake and increased circulating levels of PYY. Other approaches to nutrient-induced changes to appetite include colonic delivery of short chain fatty acid propionate, which also reduces food intake ${ }^{52}$ and increases circulating levels of PYY and GLP-1, in acute and long-term administration studies. ${ }^{23}{ }^{46}$ LA delivery leads to a small increase in serum GLP-1 levels. ${ }^{53}$ Both of these studies reported increased circulating levels of GLP-1 following nutrient delivery. This contrasts with the current trial, where GLP-1 levels were not significantly altered, yet calorific intake was lower in active versus placebo. This would suggest that circulating PYY predominates in mediating these effects. Alternatively, GLP-1 may be having a peripheral, locally mediated effect on GLP-1R receptors expressed on nearby mucosal afferent endings. This is further implicated by our electrophysiology data in mice showing potent local GLP-1R mediated effects. Finally, it is unsurprising that ghrelin levels were not significantly altered between active and placebo groups in the present study, as ghrelin is released primarily from the stomach, and the capsules used in the study were coated specifically for colonic release.

In our obese volunteer study, there was no effect of MCFA capsules on subjective hunger ratings but modest yet significant effects on energy intake. This reduction in calorific intake of approximately $12 \%$ could result in weight loss of $12 \mathrm{~kg}$ over 24 weeks (based on US National Institute of Health Guidelines) ${ }^{54}$ but requires validation in a long-term weight loss study. 
Additionally, unchanged subjective hunger ratings suggest a subliminal effect on appetite, which is a desirable feature of any obesity treatment, and one that we shall aim to retain in further larger scale clinical studies. We would speculate that this is a feature of stimulating the colon rather than the small intestine, which is a major source of signals that induce nausea, fullness and similar conscious perceptions. The data presented here warrant a chronic administration study with a larger number of volunteers to assess end-points of weight loss, examine hormone expression (over months) and assess population variability to treatment.

There are a number of limitations within the current study. For example, the absence of potent synthetic agonists for GPR84. We have used LA as it binds to the GPR84 to activate the receptor; however, this agonist may bind to other long-chain receptors. In addition, electrophysiology experiments in human colonic tissue would add a further translational advantage, while similar experiments in animal models of obesity and altered diet would provide insight to neuronal signalling pathways-these will be investigated in future studies. A clear limitation of the clinical trial using an acute administration paradigm is the lack of longer time-points for measurement of hormone release and effect on appetite perception. The capsule coating ensures colonic delivery, but this requires between 3 and 4 hours from ingestion to disintegration in the colon resulting from normal gastrointestinal motility time (as described in the Methods). As the active and placebo capsules are given over two points in a single day, it was not feasible to assess volunteers for more than 8 hours. Finally, although only CCK and ghrelin have been shown to be altered by oestradiol ${ }^{55}$ and despite inclusion of a 4-week washout to account for cycle phase of female volunteers, we cannot completely discount effect of hormonal variation in the results.

In conclusion, we demonstrate that specific targeting of multiple nutrient-sensing receptors stimulates convergent activation of EEC and colonic afferent endings. Importantly, we show that targeting colonic L cells by costimulating specific receptors in obese volunteers has the capacity to reduce food intake and boost PYY levels, thereby supporting our preclinical findings and offering the potential development of a novel and effective obesity treatment without the drawbacks of surgery. With these principles in mind, we can devise more appropriate strategies for targeting nutrient sensing in the colon for the benefit of treatment of obesity and type 2 diabetes and move on to larger scale studies including body weight regulation.

Correction notice This article has been published Online First. Reference 25 has been updated and the acknowledgements section added.

Acknowledgements We are grateful for technical advice and contribution to clinical trial material preparation from Prof Abdul Basit (The School of Pharmacy, University College London, UK), Silvia Matiz (InTract Pharma, London, UK) and Colm O'Reilly (InTract Pharma, London, UK).

Contributors MP conceived, designed and conducted experiments and managed the clinical trial. RA, AZ and WH recruited volunteers and conducted the clinical trial. DR developed the electrophysiology technique described. DR and VC-G conducted electrophysiology experiments. AR and SC performed immunohistochemistry. HD obtained biopsies and assisted with hormone/protein assay development. CK provided clinical supervision to the volunteer study. $A B$ conceived and supervised the project and obtained funding. All authors contributed to manuscript preparation.

Funding Funding for this study was obtained from the Wellcome Trust, Bowel and Cancer Research, the JP Moulton Charitable Foundation and the Biotechnology and Biological Sciences Research Council (BBSRC) Institute Strategic Programme Gut Microbes and Health BB/R012490/1 and its constituent project (BBS/E/ F/000PR10355).

Competing interests None declared.

Patient consent for publication Not required.
Ethics approval The clinical study had ethical approval from Queen Mary Ethics of Research Committee (QMREC2018/20). For human tissue specimens, ethical approval was obtained from the East London and The City HA Local Research Ethics Committee (NREC 09/H0704/2) and after written patient consent.

Provenance and peer review Not commissioned; externally peer reviewed.

Data availability statement All data relevant to the study are included in the article or uploaded as supplementary information.

Supplemental material This content has been supplied by the author(s). It has not been vetted by BMJ Publishing Group Limited (BMJ) and may not have been peer-reviewed. Any opinions or recommendations discussed are solely those of the author(s) and are not endorsed by BMJ. BMJ disclaims all liability and responsibility arising from any reliance placed on the content. Where the content includes any translated material, BMJ does not warrant the accuracy and reliability of the translations (including but not limited to local regulations, clinical guidelines, terminology, drug names and drug dosages), and is not responsible for any error and/or omissions arising from translation and adaptation or otherwise.

Open access This is an open access article distributed in accordance with the Creative Commons Attribution 4.0 Unported (CC BY 4.0) license, which permits others to copy, redistribute, remix, transform and build upon this work for any purpose, provided the original work is properly cited, a link to the licence is given, and indication of whether changes were made. See: https://creativecommons.org/ licenses/by/4.0/.

\section{ORCID iD}

Madusha Peiris http://orcid.org/0000-0003-4429-5931

\section{REFERENCES}

1 Colquitt JL, Pickett K, Loveman E, et al. Surgery for weight loss in adults. Cochrane Database Syst Rev 2014:CD003641.

2 le Roux CW, Aylwin SJB, Batterham RL, et al. Gut hormone profiles following bariatric surgery favor an anorectic state, facilitate weight loss, and improve metabolic parameters. Ann Surg 2006:243:108-14.

3 Flynn CR, Albaugh VL, Abumrad NN. Metabolic effects of bile acids: potential role in bariatric surgery. Cell Mol Gastroenterol Hepatol 2019;8:235-46.

4 Aron-Wisnewsky J, Prifti E, Belda E, et al. Major microbiota dysbiosis in severe obesity: fate after bariatric surgery. Gut 2019;68:70-82.

5 Neary NM, Small CJ, Druce MR, et al. Peptide YY3-36 and glucagon-like peptide-17-36 inhibit food intake additively. Endocrinology 2005;146:5120-7.

6 Batterham RL, Cohen MA, Ellis SM, et al. Inhibition of food intake in obese subjects by peptide YY3-36. N Eng/ J Med 2003;349:941-8.

7 Turton MD, O'Shea D, Gunn I, et al. A role for glucagon-like peptide-1 in the central regulation of feeding. Nature 1996;379:69-72.

$8 \mathrm{Xu}$ Y, Jones JE, Kohno D, et al. 5-HT2CRs expressed by pro-opiomelanocortin neurons regulate energy homeostasis. Neuron 2008;60:582-9.

9 Lieverse RJ, Jansen JB, van de Zwan A, et al. Effects of a physiological dose of cholecystokinin on food intake and postprandial satiation in man. Regul Pept 1993;43:83-9.

10 Nakazato M, Murakami N, Date Y, et al. A role for ghrelin in the central regulation of feeding. Nature 2001;409:194-8.

11 Murphy KG, Bloom SR. Gut hormones and the regulation of energy homeostasis. Nature 2006;444:854-9.

12 Valassi E, Scacchi M, Cavagnini F. Neuroendocrine control of food intake. Nutr Metab Cardiovasc Dis 2008:18:158-68.

13 Page AJ, Symonds E, Peiris M, et al. Peripheral neural targets in obesity. Br J Pharmacol 2012;166:1537-58.

14 Gribble FM, Reimann F. Enteroendocrine cells: Chemosensors in the intestinal epithelium. Annu Rev Physiol 2016;78:277-99.

15 Haber AL, Biton M, Rogel N, et al. A single-cell survey of the small intestinal epithelium. Nature 2017:551:333-9.

16 Gehart $H$, van Es JH, Hamer K, et al. Identification of enteroendocrine regulators by real-time single-cell differentiation mapping. Cell 2019;176:e16:1158-73.

17 Gunawardene AR, Corfe BM, Staton CA. Classification and functions of enteroendocrine cells of the lower gastrointestinal tract. Int J Exp Pathol 2011:92:219-31.

18 Symonds EL, Peiris M, Page AJ, et al. Mechanisms of activation of mouse and human enteroendocrine cells by nutrients. Gut 2015;64:618-26.

19 Ekberg JH, Hauge M, Kristensen LV, et al. Gpr119, a major enteroendocrine sensor of dietary triglyceride metabolites Coacting in synergy with FFA1 (GPR40). Endocrinology 2016;157:4561-9.

20 Murtaza B, Hichami A, Khan AS, et al. Novel GPR120 agonist TUG891 modulates fat taste perception and preference and activates tongue-brain-gut axis in mice. J Lipid Res 2020;61:133-42.

21 Sumithran P, Prendergast LA, Delbridge E, et al. Long-Term persistence of hormonal adaptations to weight loss. N Eng/ J Med 2011;365:1597-604. 
22 Dye L, Blundell JE. Menstrual cycle and appetite control: implications for weight regulation. Hum Reprod 1997;12:1142-51.

23 Chambers ES, Viardot A, Psichas A, et al. Effects of targeted delivery of propionate to the human colon on appetite regulation, body weight maintenance and adiposity in overweight adults. Gut 2015;64:1744-54.

24 Flint A, Raben A, Blundell JE, et al. Reproducibility, power and validity of visual analogue scales in assessment of appetite sensations in single test meal studies. Int $J$ Obes Relat Metab Disord 2000;24:38-48.

25 Ibekwe VC, Khela MK, Evans DF, et al. A new concept in colonic drug targeting: a combined $\mathrm{pH}$-responsive and bacterially-triggered drug delivery technology. Aliment Pharmacol Ther 2008;28:911-6.

26 Brookes SJH, Spencer NJ, Costa M, et al. Extrinsic primary afferent signalling in the gut. Nat Rev Gastroenterol Hepatol 2013;10:286-96.

27 Berthoud HR, Blackshaw LA, Brookes SJH, et al. Neuroanatomy of extrinsic afferents supplying the gastrointestinal tract. Neurogastroenterol Motil 2004;16 Suppl $1: 28-33$.

28 Lynn PA, Blackshaw LA. In vitro recordings of afferent fibres with receptive fields in the serosa, muscle and mucosa of rat colon. J Physiol 1999;518:271-82.

29 Daly DM, Park SJ, Valinsky WC, et al. Impaired intestinal afferent nerve satiety signalling and vagal afferent excitability in diet induced obesity in the mouse. J Physiol 2011;589:2857-70.

30 Wang J, Wu X, Simonavicius N, et al. Medium-Chain fatty acids as ligands for orphan G protein-coupled receptor GPR84. J Biol Chem 2006;281:34457-64.

31 Hudson BD, Shimpukade B, Mackenzie AE, et al. The pharmacology of TUG-891, a potent and selective agonist of the free fatty acid receptor 4 (FFA4/GPR120), demonstrates both potential opportunity and possible challenges to therapeutic agonism. Mol Pharmacol 2013;84:710-25.

32 Blackshaw LA, Grundy D. Effects of 5-hydroxytryptamine on discharge of vagal mucosal afferent fibres from the upper gastrointestinal tract of the ferret. $J$ Auton Nerv Syst 1993;45:41-50.

33 Bucinskaite V, Tolessa T, Pedersen J, et al. Receptor-Mediated activation of gastric vagal afferents by glucagon-like peptide- 1 in the rat. Neurogastroenterol Motil 2009:21:978-e78

34 Koda S, Date Y, Murakami N, et al. The role of the vagal nerve in peripheral PYY3-36induced feeding reduction in rats. Endocrinology 2005;146:2369-75.

35 Dockray GJ. Enteroendocrine cell signalling via the vagus nerve. Curr Opin Pharmacol 2013:13:954-8.

36 Berthoud HR, Neuhuber WL. Functional and chemical anatomy of the afferent vagal system. Auton Neurosci 2000:85:1-17.

37 Thorens B, Porret A, Bühler $L$, et al. Cloning and functional expression of the human islet GLP-1 receptor. Demonstration that exendin-4 is an agonist and exendin-(9-39) an antagonist of the receptor. Diabetes 1993;42:1678-82.

38 Cox HM, Tough IR, Woolston A-M, et al. Peptide YY is critical for acylethanolamine receptor Gpr119-induced activation of gastrointestinal mucosal responses. Cell Metab 2010;11:532-42.
39 Worthington JJ, Reimann F, Gribble FM. Enteroendocrine cells-sensory sentinels of the intestinal environment and orchestrators of mucosal immunity. Mucosal Immunol 2018;11:3-20.

40 Furness JB. Integrated neural and endocrine control of gastrointestinal function. $A d v$ Exp Med Biol 2016;891:159-73.

41 Reimann F, Gribble FM. G protein-coupled receptors as new therapeutic targets for type 2 diabetes. Diabetologia 2016;59:229-33.

42 Mannon PJ, Kanungo A, Mannon RB, et al. Peptide YY/neuropeptide Y Y 1 receptor expression in the epithelium and mucosal nerves of the human colon. Regul Pept 1999;83:11-19.

43 Koehler JA, Baggio LL, Yusta B, et al. Glp-1R agonists promote normal and neoplastic intestinal growth through mechanisms requiring FGF7. Cell Metab 2015;21:379-91.

44 Kapeller J, Möller D, Lasitschka F, et al. Serotonin receptor diversity in the human colon: expression of serotonin type 3 receptor subunits 5-HT3C, 5-HT3D, and 5-HT3E. J Comp Neurol 2011;519:420-32.

45 Kristensen M, Jensen MG. Dietary fibres in the regulation of appetite and food intake. Importance of viscosity. Appetite 2011;56:65-70.

46 Chambers ES, Byrne CS, Morrison DJ, et al. Dietary supplementation with inulinpropionate ester or inulin improves insulin sensitivity in adults with overweight and obesity with distinct effects on the gut microbiota, plasma metabolome and systemic inflammatory responses: a randomised cross-over trial. Gut 2019;68:1430-8.

47 Kentish SJ, O'Donnell TA, Isaacs NJ, et al. Gastric vagal afferent modulation by leptin is influenced by food intake status. J Physiol 2013:591:1921-34.

48 Raybould HE, Glatzle J, Robin C, et al. Expression of 5-HT3 receptors by extrinsic duodenal afferents contribute to intestinal inhibition of gastric emptying. Am J Physiol Gastrointest Liver Physiol 2003;284:G367-72.

49 Glatzle J, Sternini C, Robin C, et al. Expression of 5-HT3 receptors in the rat gastrointestinal tract. Gastroenterology 2002;123:217-26.

50 Grundy D, Hillsley K, Kirkup AJ, et al. Mesenteric afferent sensitivity to cholecystokinin and 5-hydroxytryptamine. Dtsch Tierarzt/ Wochenschr 1998;105:466-8.

51 Habib AM, Richards P, Cairns LS, et al. Overlap of endocrine hormone expression in the mouse intestine revealed by transcriptional profiling and flow cytometry. Endocrinology 2012;153:3054-65.

52 Polyviou T, MacDougall K, Chambers ES, et al. Randomised clinical study: inulin shortchain fatty acid esters for targeted delivery of short-chain fatty acids to the human colon. Aliment Pharmacol Ther 2016:44:662-72.

$53 \mathrm{Ma}$ J, Checklin HL, Wishart JM, et al. A randomised trial of enteric-coated nutrient pellets to stimulate gastrointestinal peptide release and lower glycaemia in type 2 diabetes. Diabetologia 2013;56:1236-42.

54 Clinical Guidelines on the Identification, Evaluation, and Treatment of Overweight and Obesity in Adults--The Evidence Report. National Institutes of Health. Obes Res 1998:6 Suppl 2:51S-209S.

55 Butera PC. Estradiol and the control of food intake. Physiol Behav 2010;99:175-80. 